\title{
Residual aortic regurgitation after transcatheter aortic valve replacement under the echocardiographic microscope
}

\author{
Michael J. Reardon, MD, ${ }^{\mathrm{a}}$ and Jeffrey J. Popma, $\mathrm{MD}^{\mathrm{b}}$
}

\footnotetext{
From the ${ }^{\text {aDepartment }}$ of Cardiovascular Surgery, Houston DeBakey Heart \& Vascular Center, Houston, Tex; and ${ }^{\mathrm{b}}$ Department of Medicine, Beth Israel Deaconess Medical Center, Harvard Medical School, Boston, Mass. Disclosures: Michael J. Reardon is on the Advisory Board of Medtronic, and received an Institutional grant from Medtronic. Jeffrey J. Popma received Institutional grants from Medtronic, Boston Scientific, and Direct Flow Medical. He also receives consulting fees from Boston Scientific for the Medical Advisory Board and consulting fees and equity from Direct Flow Medical.

Received for publication June 13, 2016; accepted for publication June 16, 2016; available ahead of print July 12, 2016.

Address for reprints: Michael J. Reardon, MD, Department of Cardiovascular Surgery, Houston DeBakey Heart \& Vascular Center, 6550 Fannin, Suite 1401, Houston, TX 77030 (E-mail: mreardon@ houstonmethodist.org). J Thorac Cardiovasc Surg 2016;152:659-60 $0022-5223 / \$ 36.00$

Copyright (C) 2016 by The American Association for Thoracic Surgery http://dx.doi.org/10.1016/j.jtcvs.2016.06.021
}

Transcatheter aortic valve replacement (TAVR) for patients with severe aortic stenosis has expanded dramatically in patients deemed suboptimal for surgical aortic valve replacement (SAVR). The explosive growth of TAVR has been supported by unparalleled clinical trial data in specifically defined patient subsets, with equal or superior survival and stroke rates,${ }^{1-3}$ improved early quality of life, ${ }^{4}$ lower major adverse clinical events, ${ }^{1}$ and improved systolic flow parameters, ${ }^{1}$ including lower rates of patient prosthetic mismatch $^{5}$ when compared with SAVR.

Iterative transcatheter design improvements have focused on reducing complications associated with TAVR, including vascular complications, by reducing the delivery catheter profile, lessening periprocedural complications, and lowering rates of residual aortic valve regurgitation (AR). ${ }^{6,7}$ For the latter finding, the Valve Academic Research Consortium has provided standardized criteria for assessing residual aortic regurgitation, categorizing the degree of residual AR into 4 categories: none, mild, moderate, and severe. ${ }^{8,9}$ Although trace $\mathrm{AR}$ was not specifically defined in VARC- $1,{ }^{8}$ VARC- $2,{ }^{9}$ or the Trancatheter Valve Therapies Registry, ${ }^{10}$ it has generally been characterized in both clinical trials and clinical practice. Using these rigorous criteria, mild AR and moderate residual AR have been correlated with incrementally worse outcomes after TAVR. ${ }^{11}$ While it is understandable that moderate or severe AR would be associated with a worsened outcome after TAVR, the pathologic relationship of mild residual AR and late mortality is less clear, attributable to observer variability, to a too broad categorization of mild AR that includes patients with hemodynamically significant residual AR, or to changes in ventricular performance with $A R$ in a thickened ventricle that adversely affect ventricular recovery after TAVR. ${ }^{12}$ A unifying classification system that includes expanded the grading system to 7 categories (adding trace, mild-moderate, and moderate-severe to

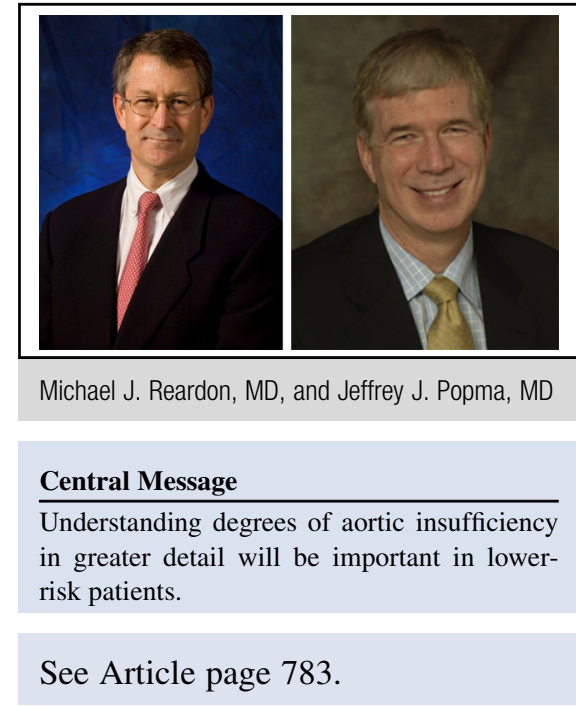

none, mild, moderate, and severe) has been proposed, but the clinical importance of a more expanded grading system has not been validated. ${ }^{12}$

In the current article by Jones and colleagues, ${ }^{13}$ the value of a 9-grade system of aortic regurgitation after transfemoral TAVR using Sapien or Sapien XT valves was evaluated in 237 patients. The authors report a unit hazard ratio of 2.26 (95\% confidence interval, $1.48-3.43 ; P<.001)$ for 1 year mortality for each $1+$ increase in AR after TAVR, ranging from no 1-year mortality for patients with no AR to $50 \%$ in those patients with 2 to $3+$ AR. Several items are noteworthy about this important analysis. First, the relationship of mild AR using conventional clinical grading criteria is confirmed in this study (13.2\% 1-year mortality vs $33.3 \%$ mortality in the moderate AR group and no mortality in the no AR group). Second, while one would have hoped that this more granular grading system would have differentiated outcomes in the conventional mild group, the 1 -year mortality rate was $16.9 \%$ in the $1+$ mild group $(1+)$ and $18.5 \%$ in the 1 to $2+$ mild-moderate group. It is possible that larger numbers of patients will better differentiate outcomes in the mild and mild-moderate groups, an important finding to tie the pathophysiology of residual AR and late ventricular performance. Third, the authors report paravalvular AR in this report, rather than total residual AR. Although the linear trend for late outcome is likely similar, reporting only paravalvular AR does not include patients with transvalvular AR or those patients in whom the location of the AR could not be determined as paravalvular. 
It is likely that the absolute rates of total residual AR would be higher. Finally, the authors were not able to fully evaluate the value of higher grades of AR because few patients experienced moderately severe and severe AR. It is intuitive that this would be an unacceptable TAVR result and mandates additional interventions to reduce the AR.

The key question for this report is whether a more microscopic analysis of the echocardiographic grading of residual AR enhances our understanding of late outcomes after TAVR. It clearly does. Although a 9-point grading system may be a little too granular, as data are limited with the more severe grades, this analysis does support movement toward the more expanded grading system proposed by Pibarot and colleagues. ${ }^{12}$ It is to be hoped that these data will be considered with the next iteration of VARC. It is also critical to understand that very large sample sizes $(>2000$ patients) may be required to fully understand the clinical impact of relationships caused by type II errors resulting from lower clinical event rates.

So why is there so much attention on assessing residual AR after TAVR? With ongoing randomized evaluations comparing surgery and TAVR in lower-risk patients with aortic stenosis, long-term valve durability and residual aortic regurgitation become central issues. Although demonstration of valve durability will require a 5- to 10 year follow-up, immediate assessment of residual AR is critical, as it can be mitigated at the time of the procedure with corrective maneuvers, such as balloon postdilation, valve-in-valve, or paravalvular leak closure. It is clear that residual AR is more common after TAVR than SAVR, ${ }^{1,2}$ whereas prosthesis patient mismatch is more common in patients with SAVR than with TAVR. ${ }^{5,14}$ The overall benefit of TAVR in elderly patients suboptimal for surgery seems to favor TAVR over surgery, ${ }^{15}$ but it is less clear that this balance will be maintained in lower-risk patients who wish to remain active after valve replacement and will have longer life expectancies. Much attention has been paid to iterative transcatheter designs that reduced residual AR, such as sealing skirts with the SAPIEN $3^{6}$ and Evolut-R 2.0 designs, an adaptive seal with the Lotus device, ${ }^{16}$ and ventricular and aortic sealing rings with Direct Flow Medical. Large clinical studies will address the value of these novel designs on clinical outcomes. Pending these results, the current study provides important evidence that outcomes should be assessed with the highest level of echocardiographic scrutiny possible.

\section{References}

1. Deeb GM, Reardon MJ, Chetcuti S, Patel HJ, Grossman PM, Yakubov SJ, et al. 3-Year outcomes in high-risk patients who underwent surgical or transcatheter aortic valve replacement. J Am Coll Cardiol. 2016;67:2565-74.

2. Mack MJ, Leon MB, Smith CR, Miller DC, Moses JW, Tuzcu EM, et al. 5-Year outcomes of transcatheter aortic valve replacement or surgical aortic valve replacement for high surgical risk patients with aortic stenosis (PARTNER 1): a randomised controlled trial. Lancet. 2015;385:2477-84.

3. Kapadia SR, Leon MB, Makkar RR, Tuzcu EM, Svensson LG, Kodali S, et al. 5Year outcomes of transcatheter aortic valve replacement compared with standard treatment for patients with inoperable aortic stenosis (PARTNER 1): a randomised controlled trial. Lancet. 2015;385:2485-91.

4. Arnold SV, Reynolds MR, Wang K, Magnuson EA, Baron SJ, Chinnakondepalli KM, et al. Health status after transcatheter or surgical aortic valve replacement in patients with severe aortic stenosis at increased surgical risk: results from the CoreValve US Pivotal Trial. JACC Cardiovasc Interv. 2015;8:1207-17.

5. Zorn GL III, Little SH, Tadros P, Deeb GM, Gleason TG, Heiser J, et al. Prosthesis-patient mismatch in high-risk patients with severe aortic stenosis: a randomized trial of a self-expanding prosthesis. J Thorac Cardiovasc Surg. 2015; 151:1014-23.

6. Thourani VH, Kodali S, Makkar RR, Herrmann HC, Williams M, Babaliaros V, et al. Transcatheter aortic valve replacement versus surgical valve replacement in intermediate-risk patients: a propensity score analysis. Lancet. 2016;387: 2218-25.

7. Manoharan G, Walton AS, Brecker SJ, Pasupati S, Blackman DJ, Qiao H, et al. Treatment of symptomatic severe aortic stenosis with a novel resheathable supraannular self-expanding transcatheter aortic valve system. JACC Cardiovasc Interv. 2015;8:1359-67.

8. Leon MB, Smith CR, Mack M, Miller DC, Moses JW, Svensson LG, et al. Transcatheter aortic-valve implantation for aortic stenosis in patients who cannot undergo surgery. N Engl J Med. 2010;363:1597-607.

9. Kappetein AP, Head SJ, Genereux P, Piazza N, van Mieghem NM, Blackstone EH, et al. Updated standardized endpoint definitions for transcatheter aortic valve implantation: the Valve Academic Research Consortium-2 consensus document. J Thorac Cardiovasc Surg. 2013;145:6-23.

10. Holmes DR Jr, Brennan JM, Rumsfeld JS, Dai D, O’Brien SM, Vemulapalli S, et al. Clinical outcomes at 1 year following transcatheter aortic valve replacement. JAMA. 2015;313:1019-28.

11. Kodali S, Pibarot P, Douglas PS, Williams M, Xu K, Thourani V, et al. Paravalvular regurgitation after transcatheter aortic valve replacement with the Edwards sapien valve in the PARTNER trial: characterizing patients and impact on outcomes. Eur Heart J. 2015;36:449-56.

12. Pibarot P, Hahn RT, Weissman NJ, Monaghan MJ. Assessment of paravalvular regurgitation following TAVR: a proposal of unifying grading scheme. JACC Cardiovasc Imaging. 2015;8:340-60.

13. Jones B, Tuzcu E, Krishnaswamy A, Popovic Z, Mick S, Roselli E, et al. Prognostic significance of mild AR in predicting mortality after TAVR. J Thorac Cardiovasc Surg. 2016;152:783-90.

14. Pibarot P, Weissman NJ, Stewart WJ, Hahn RT, Lindman BR, McAndrew T, et al. Incidence and sequelae of prosthesis-patient mismatch in transcatheter versus surgical valve replacement in high-risk patients with severe aortic stenosis: a PARTNER trial cohort-a analysis. J Am Coll Cardiol. 2014;64: 1323-34.

15. Kaul S. Transcatheter aortic-valve replacement with a self-expanding prosthesis. N Engl J Med. 2014;371:967.

16. Meredith IT, Walters DL, Dumonteil N, Worthley SG, Tchetche D, Manoharan G, et al. 1-Year outcomes with the fully repositionable and retrievable Lotus transcatheter aortic replacement valve in 120 high-risk surgical patients with severe aortic stenosis: results of the REPRISE II study. JACC Cardiovasc Interv. 2016;9:376-84. 